\title{
Synoptic Variation of the Radio Refractive Index
}

\author{
B. R. Bean and L. P. Riggs
}

(January 22, 1959)

\begin{abstract}
The synoptic variation of the atmospheric radio refractive index, evaluated from standard weather observations, is examined during an outbreak of polar continental air. It is found that the reduced-to-sea-level value of the refractive index is a more sensitive synoptic parameter than the station value. The reduced value is quite sensitive to the humidity and density structure of the storm under study while the great station elevation dependence of the station value tends to mask synoptic changes. The reduced value changes systematically with the approach and passage of the polar front. The present system shows a consistent increase of the reduced value in the warm sector of the wave and a marked decrease behind the cold front.
\end{abstract}

\section{Introduction}

The fact that the refractive index is readily determined from the standard weather observations taken in all parts of the world has led to many attempts to utilize it for the prediction of various properties of radio field strengths, particularly at frequencies in excess of about $30 \mathrm{Mc}$. It was noted early $[1,2]^{1}$ that the seasonal cycle of vhf radio field strengths recorded far beyond the normal radio horizon was highly correlated with the refractive index. A further examination $[3,4]$ has shown that this correlation was about 0.9 when both variables were taken on a monthly mean basis but decreased rapidly for shorter mean periods. For example, 10-day means yielded a correlation coefficient of about 0.8, 5-day means about 0.7 , and individual observations for a given hour each day throughout the year yielded a correlation coefficient of 0.5 . The high correlation on a monthly mean basis is utilized by Norton [5] and Gray [6] to predict seasonal and geographic variations of radio field strengths. A recent experimental check of Norton's method with radio field strengths recorded in Japan [4] shows the same high correlation of about 0.9 . The purpose of the present paper is to examine the synoptic variations of $N_{s}$ and, although the correlations are not as high as those on a monthly mean basis, one may use Norton's or Gray's method as a useful guide of the day-to-day variation of radio field strengths.

The value of the refractive index of the atmosphere, $n$, may be determined from the expression for refractivity, $N$ [7]:

$$
N=(n-1) 10^{6}=\frac{77.6}{T}\left(P+\frac{4810 e_{s} R H}{T}\right),
$$

which has been shown to be in error by no more than 0.5 percent in the frequency range 0 to $30,000 \mathrm{Mc}$. Equation (1) may be evaluated from standard weather observations since it is a function of the atmospheric pressure, $P$, in millibars and the partial pressure of water vapor as expressed by the product of the relative humidity in percent, $R H$, and the saturation

\footnotetext{
*This work was sponsored in part by task 31 of the U.S. Navy Weather Research Facility, Norfolk, Va.

1 Figures in brackets indicate the literature references at the end of this paper.
}

vapor pressure, $e_{s}$, for the temperature $T$ in degrees Kelvin. When $N$ is determined from the values of $P$, $T$ and $R H$ of the common surface weather observation it is denoted as $N_{s}$.

Another application of the instantaneous values of $N_{s}$ is to the problem of radar elevation angle errors. It has been known for some time that the total bending or refraction of radio rays as they pass from the earth's surface upwards through the atmosphere may be expressed as a linear function of $N_{s}$ [8] for rays departing at initial elevation angles in excess of about 10 deg. Recent statistical studies [9] have shown that this linear dependence of ray bending upon $N_{s}$ may be extended to initial elevation angles of $0.5^{\circ}$ with no regard to the refractive index profile, and to $0^{\circ}$ for all $N$ profiles but ducting. Further, recent papers $[10,11]$ have shown that a very effective model of the radio refractive index structure of the atmosphere for radio ray tracing purposes may be specified from a knowledge of the surface value alone. These latter applications are of direct utility when considering such problems as radar tracking of earth satellites or radio communications with space vehicles.

With the above applications as motivation plus a curiosity as to the synoptic potential of $N$, a rather detailed analysis of a single outbreak of polar continental air was studied.

The storm sequence chosen for analysis was a rather well-developed one with strong temperature and humidity contrasts between the air masses within the warm sector and behind the cold front. This strong contrast was one of the main reasons for studying this particular sequence, since, if the refractive index is not a good synoptic indicator in this case, then there is little hope of its being one in more subtle synoptic disturbances. The following sections will be concerned with examining the degree to which $N$ does describe this particular storm.

Before proceeding with the $N$ analysis of this storm, it might be well to review briefly the idealized distribution of air masses around a polar front wave. The region of interaction between the cold air of the poles and the warm air of the tropics is referred to as the polar front and is generally located between 
$30^{\circ}$ to $60^{\circ} \mathrm{N}$. From time-to-time a section of the polar front is displaced northward by a flow of warm tropical air while an adjacent section is simultaneously displaced southward by a flow of polar air. The interaction of the flow of polar and tropical air results in the formation of a "wave" that moves along the polar front, often for thousands of miles. An example of a fully developed polar front wave is shown on figure 1 (a) in the same manner that it would appear on the daily weather map. Across the great plains and eastern seaboard of the United States, the polar front wave normally moves along the line $\mathrm{AB}$ in figure 1(a). An idealized space cross section along the line $A B$ is shown in figure 1(b). The warm tropical air that flows into the warm sector of the wave overrides the cool air before the wave to form the transition zone denoted as a worm front. The cold front represents the transition between the humid air of the warm sector that has been forced upwards and the advancing cold polar air. Squall lines are drawn to represent a belt of vigorous vertical convection and sharp wind shifts that frequently precede fastmoving cold fronts. The fronts and squall lines shown on the daily weather map represent the ground intersection of the transition zones between the various air masses.

The reader who wishes a critical appraisal of the present meteorological thinking on fronts, air masses, squall lines, etc., is referred to Dynamic Meteorology and Weather Forecasting, by Godske, Bergeron, Bjerknes, and Bundgaard, American Meteorological Society and Carnegie Institute of Washington, 1957.

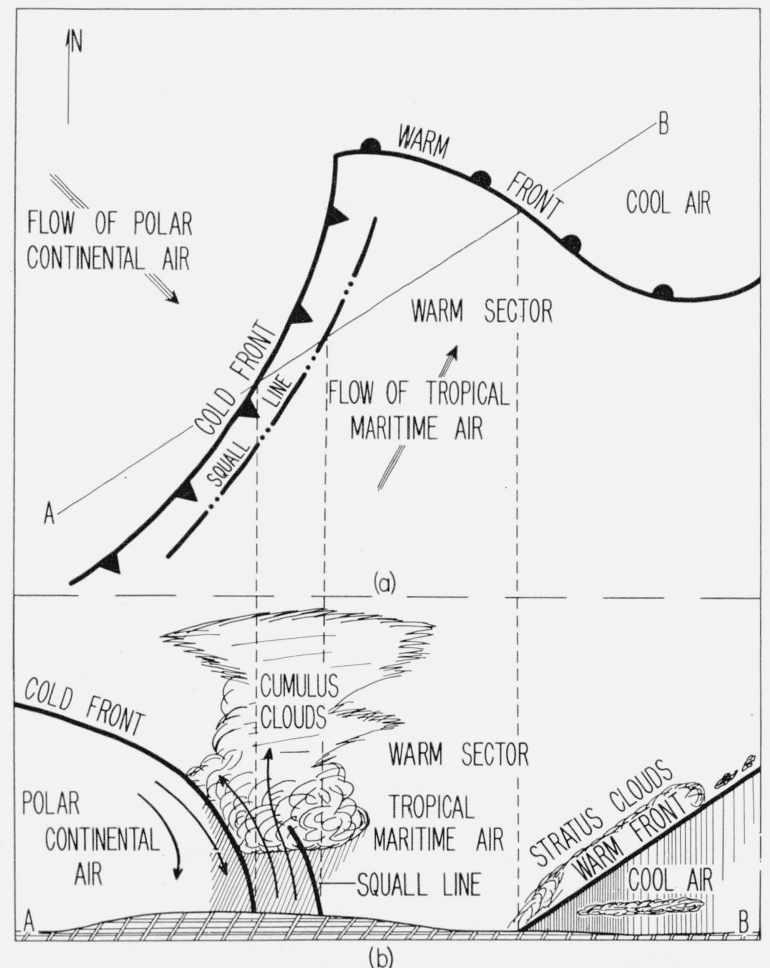

Figure 1. Idealization of a polar front wave. Cross hatching represents area of rain.

\section{Storm of 18 to 21 February 1952}

The particular example chosen for study was the outbreak of polar air during the period 18 to 21 February 1952 during which a pronounced cold front developed and moved rapidly across the United States. The synoptic sequence is seen on figures 2 through 5 where contours of $\mathrm{N}_{s}$ are derived for four stages of this storm and compared to the superimposed Weather Bureau frontal analysis. This same procedure was followed throughout the present study; i.e., contours were derived first and then compared with the frontal pattern. The black dots: on figure 8 indicate the 62 weather stations which were used to prepare the surface weather maps.

At the start of the sequence, a frontal system had come in from the Pacific Northwest and was composed of a cold front extending from northern Utah southwards into Arizona and a stationary front extending northeastwards into Wyoming. This frontal system was very slow moving for several days prior to the start of our sequence. With the outbreak of polar continental air east of the Rocky Mountains, this first front became more active and, as it moved ahead of the fast-moving polar continental front

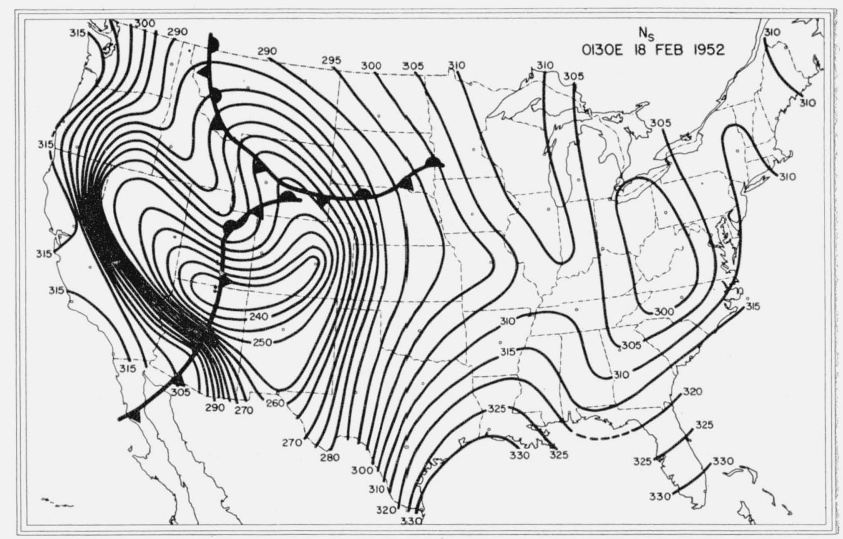

Figure 2. Radio refractivity evaluated from Weather Bureau surface observations at 0130 e.s.t., 18 Feb. 1952.

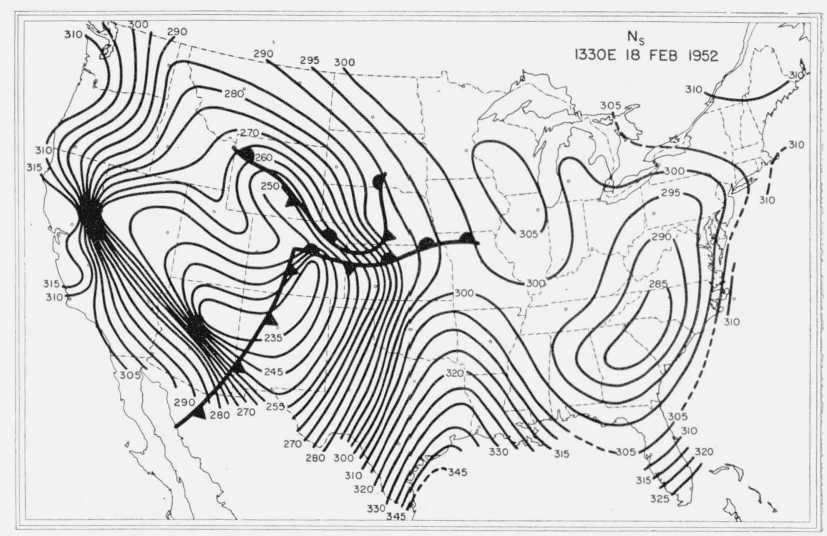

FIGURE 3. Radio refractivity evaluated from Weather Bureau surface observations at 1330 e.s.t., 18 Feb. 1952. 


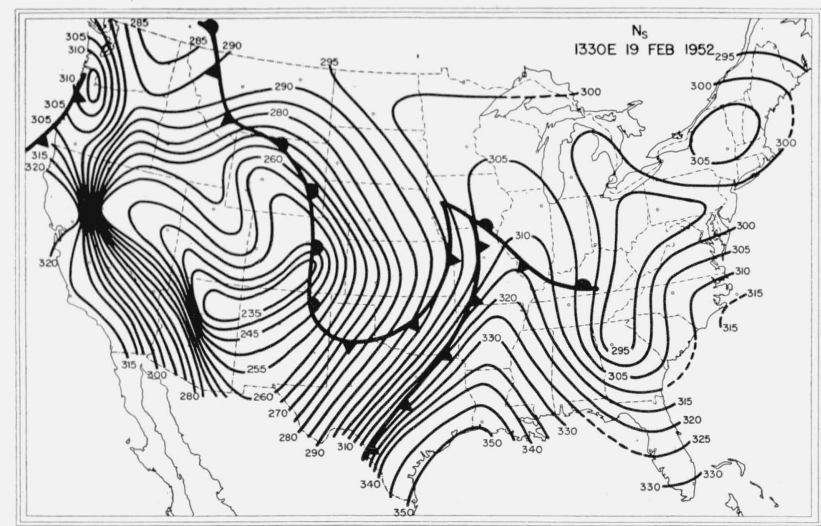

FIGURE 4. Radio refractivity evaluated from Weather Bureau surface observations at 1330 e.s.t., 19 Feb. 1952.

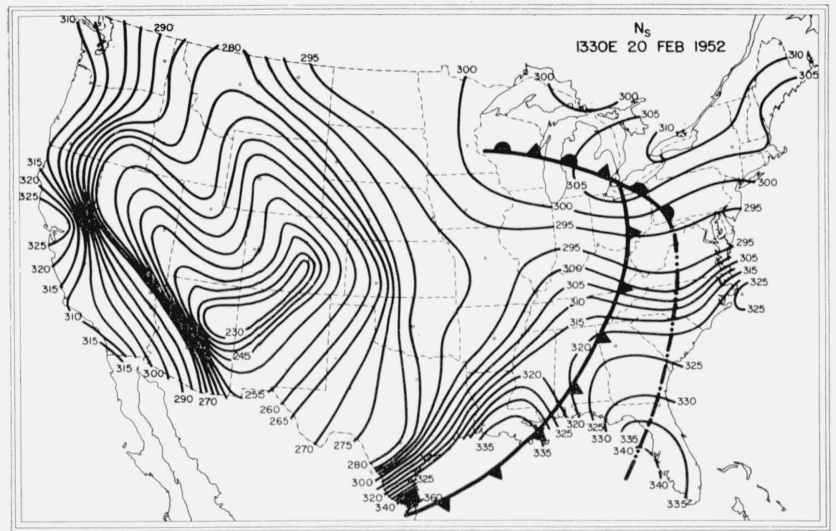

Figure 5. Radio refractivity evaluated from Weather Bureau surface observations at 1330 e.s.t., 20 Feb. 1952.

sweeping across the great plains, was reported as a squall line by the time it crossed the Mississippi River early on the morning of the 20th of February. During the latter part of the sequence, the polar maritime cold front-squall line was located in the developing warm sector of the polar front wave. The entire frontal system of cold front, polar front wave, and squall line then moved rapidly to the east coast by the morning of the 21 st, thus completing the sequence.

\section{3. $N$ as a Synoptic Indicator}

The dominant features of the $N_{s}$ contours of figures 2 to 5 remain essentially unchanged by the passage of the frontal systems and the intrusion of cold air into the central part of the country. This is evident from the extremely time-stable map features such as the steep $N_{s}$ gradient across the Sierra Nevada Mountains and the drop of $N_{s}$ value with increasing elevation across the great plains between the Mississippi River and the Rocky Mountains. The semipermanent tongue of high values of $N_{s}$ intruding up the Mississippi River Valley does show an intensification and weakening with the passage of the frontal systems. The conclusion one reaches, then, is that $N_{s}$ as such is not a particularly sensitive indicator of synoptic weather patterns.

This time stability of $N_{s}$ patterns bears a rather marked similarity to contours of ground elevation above sea level, and thus one might suspect this height dependence to be associated with the pressure term in $N$. Meteorologists have long recognized that contours of station pressure tend to mask any synoptic pattern occurring over rapidly changing terrain. The variation of station pressure with altitude is so great compared with that associated with tropospheric storms that it is necessary to effectively remove this height dependence by reducing the station pressure to sea level in order to see more clearly the pressure variations due to the storm. A similar situation seems to exist with respect to $N_{s}$. To illustrate that this is indeed the case, let us restrict our attention to the data of 1330 e.s.t. on the 19th of February (fig. 4) where the polar front is located over the midwest. By separating $N_{s}$ into a dry component, $D_{s}$, given by

$$
D_{s}=\frac{77.6 P}{T}
$$

and a wet component, $W_{s}$, given by

$$
W_{s}=\frac{77.6(4810) e_{s} R H}{T^{2}},
$$

we will be able to discuss the height dependence more thoroughly since the station pressure (which is very height dependent) is contained in the dry term and the water-vapor pressure (which is sensitive to synoptic air mass changes) is confined to the wet term. Contours of $D_{s}$ and $W_{s}$ are given on figures 6 and 7 for 1330 e.s.t. on the 19th. Compare these contours with those of $N_{s}$ for the same time (fig. 4). Note the similarity between $N_{s}$ and $D_{s}$ contours across the northern great plains and across the Sierra Nevada Mountains. It is evident that $D_{s}$ and $N_{s}$ have a similar dependence upon station elevation. Significantly, $D_{s}$ contours do not seem to reflect the pressure pattern of the frontal system in the midwest. The contours of $W_{s}$, however, show a very flat gradient throughout the mountain regions but a relatively large gradient around the polar front wave. In fact, the $W_{s}$ contours are extremely suggestive of the flow of warm, moist air into the warm sector of a classical textbook example of a polar-front wave.

It would seem that the variations of the dry term due to tropospheric storms would be more clearly indicated if its dependence upon station elevation were minimized. An arbitrary method of accomplishing this was adopted by noting that $D_{s}$ is proportional to air density and then determining that the sea-level dry term, $D_{0}$, could be written:

$$
D_{0}=D_{s} \exp \{0.1057 h\},
$$

where $h$ is in kilometers and the coefficient 0.1057 
was empirically determined from the density-height distribution of the NACA dry standard atmosphere. Contours of $D_{0}$ were determined for the same synoptic situation as figure 4 and are shown on figure 8 . It is immediately noted that the strong station elevation dependence of $D_{s}$ is not in evidence in the $D_{0}$ chart. Further, the $D_{0}$ contours about the polar front wave are extremely suggestive of the air density distribution that one would expect; namely, simultaneous intrusion of dense air in the cold air mass behind the cold front accompanied by a northerly flow of warmer, less dense air from the Gulf of Mexico into the warm sector of the frontal system.

The status of the study at this point is that $N_{s}$ and $D_{s}$ do not appear to be particularly as sensitive to synoptic changes as are $D_{0}$ and $W_{s}$. We might proceed by analyzing our particular synoptic sequence in terms of $D_{0}$ and $W_{s}$ but this seems unnecessarily complex. A simplification that suggests itself is to reduce $N_{s}$ to sea level by the very same reduction factor as used on the dry term:

$$
N_{0}=\left(D_{s}+W_{s}\right) \exp \{0.1057 h\} .
$$

The contours of $N_{0}$ for the same data used on figures $4,6,7$, and 8 are shown on figure 10 . These con-

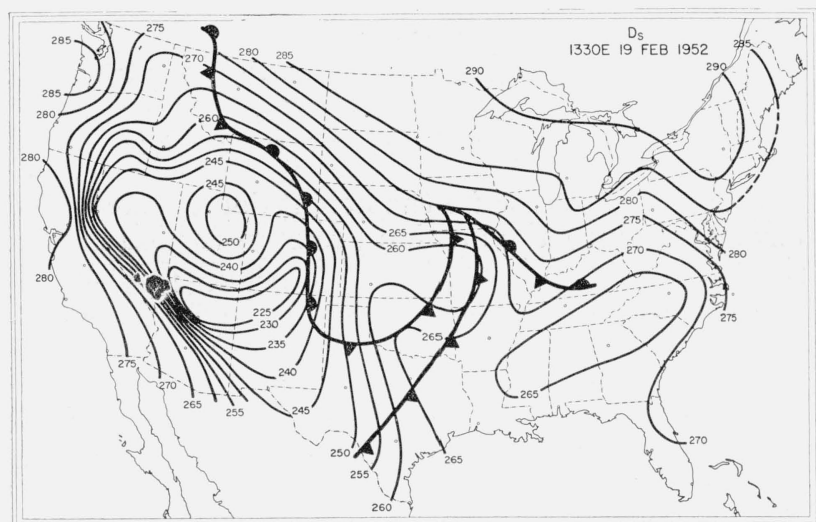

FIgURE 6. Air density component of the radio refractivity evaluated from Weather Bureau surface observations at 1330 e.s.t., 19 Feb. 1952.

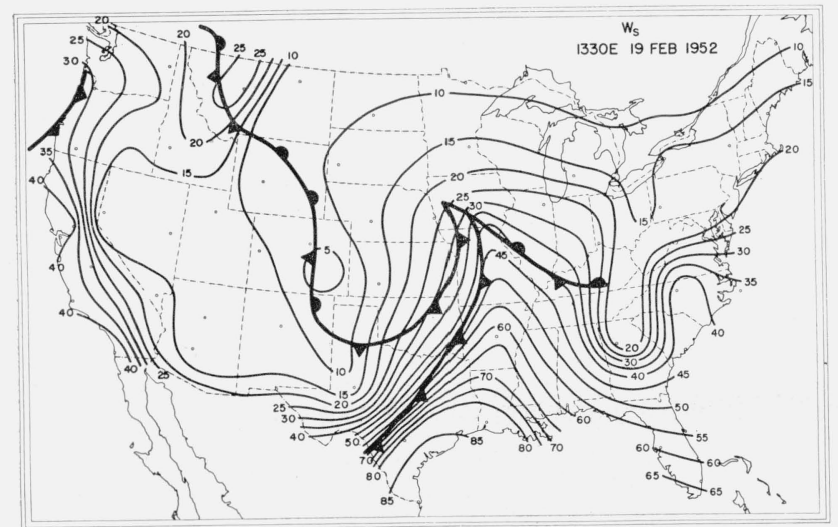

FIGURE 7. Water vapor component of the radio refractivity evaluated from Weather Bureau surface observations at 1330 e.s.t., 19 Feb. 1952.

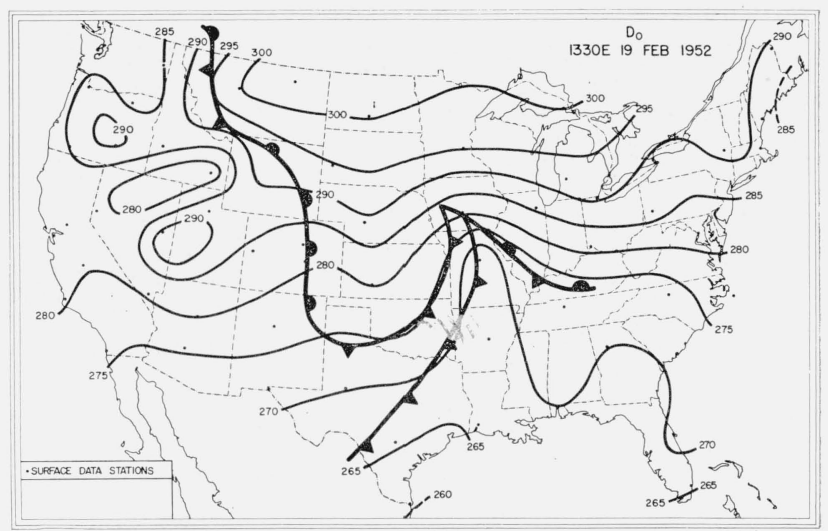

FIgURE 8. Reduced-to-sea-level value of the air density component of the radio refractivity for 1330 e.s.t., 19 Feb. 1952.

tours of $N_{0}$ seem to exhibit the desired properties of a synoptic parameter; namely, a relative insensitivity to variations in station height combined with a marked sensitivity to the density and humidity structure of tropospheric storms. Thus the following analysis of the polar outbreak of 18 to 21 February, 1952 will be in terms of $N_{0}$. A further advantage of the use of $N_{0}$ is that $N_{s}$ may easily be recovered from it for any practical application such as the determination of total atmospheric refraction.

One might wonder at the advisability of arbitrarily reducing the wet term by the dry term correction factor. For the coastal areas of the country, where the exponential height correction factor is nearly one, this amounts simply to adding the $D_{0}$ and $W_{s}$ maps while for the mountain areas, where the height correction is large but $W_{s}$ is small, it amounts to simply reducing $D_{s}$ to $D_{0}$ with the result that the gradiant of $N$ isopleths obtained from the $D_{0}$ and $W_{s}$ maps is essentially maintained on the $N_{0}$ maps.

A further advantage of $N_{0}$ over $N_{s}$ is that it is obviously more simple to prepare charts of $N_{0}$. The contours of $N_{0}$ are more widely spaced and there are fewer of them.

\section{4. $N_{0}$ Analysis of the Storm of 18 to 21 February 1952}

Charts of $N_{0}$ were prepared from the Weather Bureau surface observations taken every $24 \mathrm{hr}$ from 1330 e.s.t., February 18 until 1330 e.s.t., February 20, 1952 , or, in other words, the period of time that it took the polar front wave to develop and move across the country. The $N_{0}$ contours are compared for these times on figures 9 to 11 . These charts appear to indicate that the cold front that originally extended from Utah southward is a rather weak one since it does not seem to have much $N_{0}$ change associated with it. In the early stages of our sequence, this lack of air mass contrast is evidenced by the slight change of the position of the $N_{0}=290$ contour encircling west Texas and New Mexico as the frontal system moves through that area. By comparison, the cold front that sweeps down across the great 


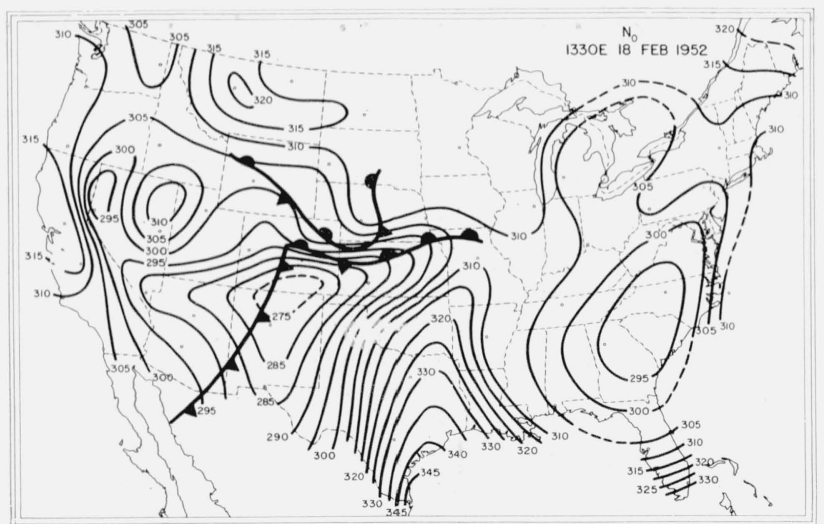

Figure 9. Reduced-to-sea-level radio refractivity, 1330 e.s.t., 18 Feb. 1952.

plains has a rather marked $N_{0}$ gradient across the front, due in large measure to the northward flow of warm moist air that forms a definite warm sector by 1330 e.s.t. on the 19 th. It is perhaps significant that the $N_{0}$ contours indicate that the various frontal systems are transition zones rather than the sharply defined discontinuities of the text book examples, a point that has been recently enlarged upon by Palmer [12].

The variation of $N_{0}$ due to the frontal system can be seen on figures 12 and 13 where examples of the 24-hr changes of $N_{0}$ have been contoured. The 24-hr change, designated $\Delta N_{0}$, was obtained by subtracting from the present value the value of $N_{0}$ observed 24 ago. The change was determined on a $24-\mathrm{hr}$ basis in order to remove any effects of the diurnal cycle of $N_{0}$. The $\Delta N_{0}$ charts show a rise of $N_{0}$ in the warm sector and a drop in $N_{0}$ behind the front amounting to $+35 N$ units in the warm sector by 1330 e.s.t. on the 20th accompanied by a 40 to $50 N$-unit drop behind the front. The relative sensitivity of $N_{0}$ to humidity changes is emphasized by the $\Delta N_{0}$ charts.

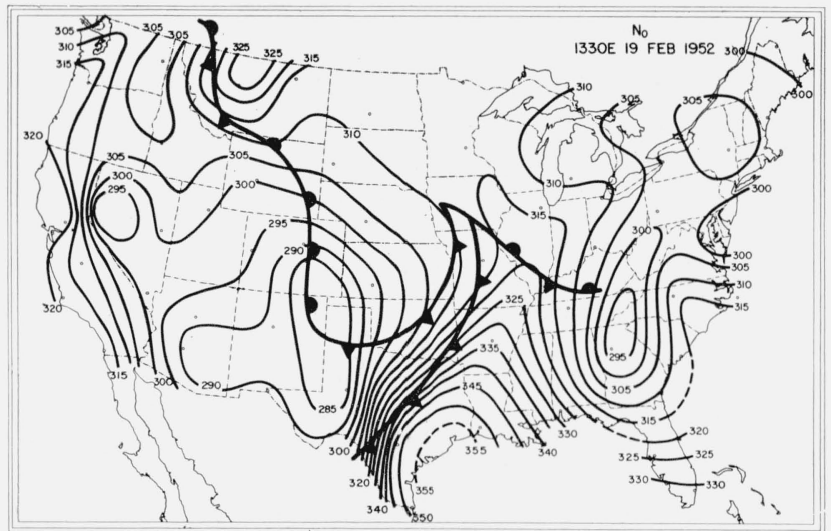

Figure 10. Reduced-to-sea-level radio refractivity, 1330 e.s.t. 19 Feb. 1952.

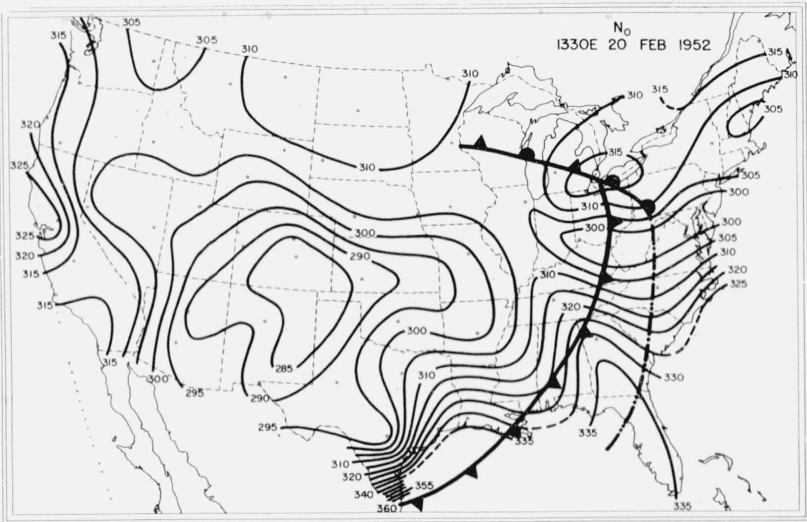

Figure 11. Reduced-to-sea-level radio refractivity, 1330 e.s.t., 20 Feb. 1952.

Consider the $N$ drop behind the cold front. This is a region of increasing pressure and decreasing temperature - a combination that increases the dry term while the rapidly dropping dewpoint decreases the wet term. The decrease in the wet term more than compensates for the increased dry term. As an example, in the $24-\mathrm{hr}$ period ending 0130 e.s.t. on the 19th, the station pressure at Oklahoma City increased 13 millibars, the dry term increased 12 $N$-units while the wet term dropped $42-N$ units giving a net change of $-30-N$ units. This $N_{0}$ rise in the warm sector and drop behind the cold front is consistent throughout the development of the polar front wave and appears to be what one would expect for this type of weather system.

The preceding maps appear to indicate that $N_{0}$ does reflect frontal system changes and that, with extensive studies of other cases, a system of objective forecasting of this parameter might be developed. Although this conclusion is based upon a study of a single storm, it appears to be borne out by preliminary analysis of other frontal systems.

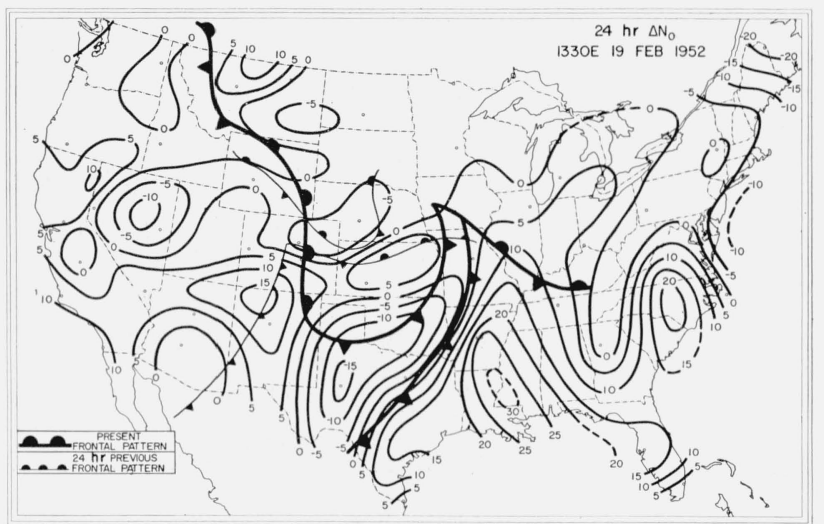

FiguRE 12. Change in the reduced-to-sea-level refractivity for the 24-hr period ending 1330 e.s.t., 19 Feb. 1952. 


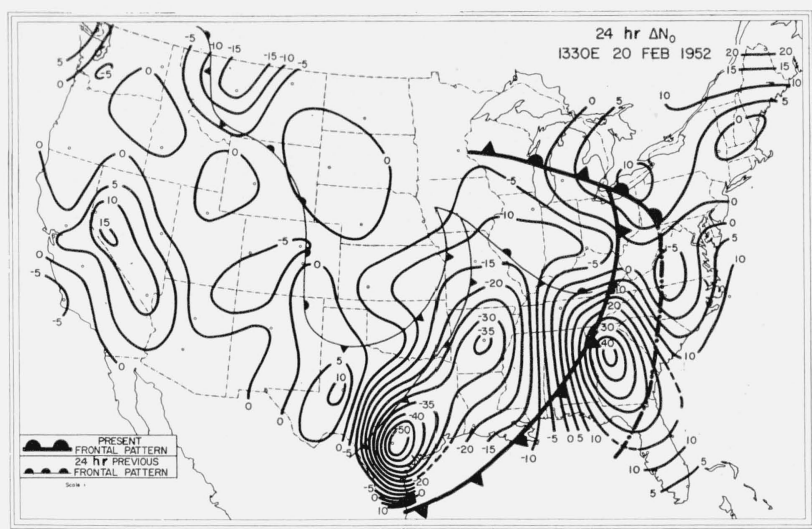

Figure 13. Change in the reduced-to-sea-level refractivity for the 24-hr period ending 1330 e.s.t., 20 Feb. 1952.

\section{Upper Air Analysis}

Another facet of the synoptic variation of $N$ is its three dimensional change with the passage of frontal systems. The $850-\mathrm{mb}(5,000 \mathrm{ft}$ above m.s.l.) and the $700-\mathrm{mb}(10,000 \mathrm{ft}$ above m.s.l.) charts were prepared for the times of radiosonde ascent (10 a.m. and 10 p.m. e.s.t.) throughout the synoptic sequence from the radiosonde reports of 43 U.S. sounding stations. It was not necessary to reduce the $850-\mathrm{mb}$ or $700-\mathrm{mb}$ level data since all of this data was already referenced to the indicated constant pressure level. Although as many maps of $N$ at the $850-\mathrm{mb}$ level, $N_{850}$, and 700-mb level, $N_{700}$, were prepared as there were $N_{0}$ maps, only two examples are chosen to illustrate the $N$ changes aloft. The $N_{850}$ and $N_{700}$ contours are shown on figures 14 to 17 while their respective 24 -hr changes, $\Delta N_{850}$ and $\Delta N_{700}$, given on figures 18 to 19 .

These $N_{850}$ charts show that the northerly flow of warm humid air within the warm sector that was so prominent in the $N_{0}$ maps is also clearly in evidence at the 5,000-ft level. Further, a change pattern similar to that on the $N_{0}$ maps is also observed at the $850-\mathrm{mb}$ level; i.e., a rise in $N_{0}$ value in the warm sector and a decrease behind the cold front. Sur-

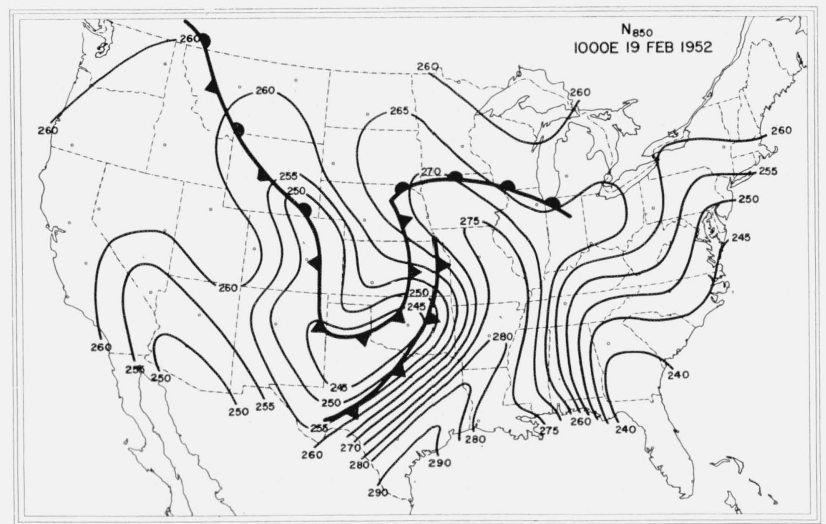

FIGURE 14. Radio refractivity at the 850-mb level 1000 e.s.t., 19 Feb. 1952.

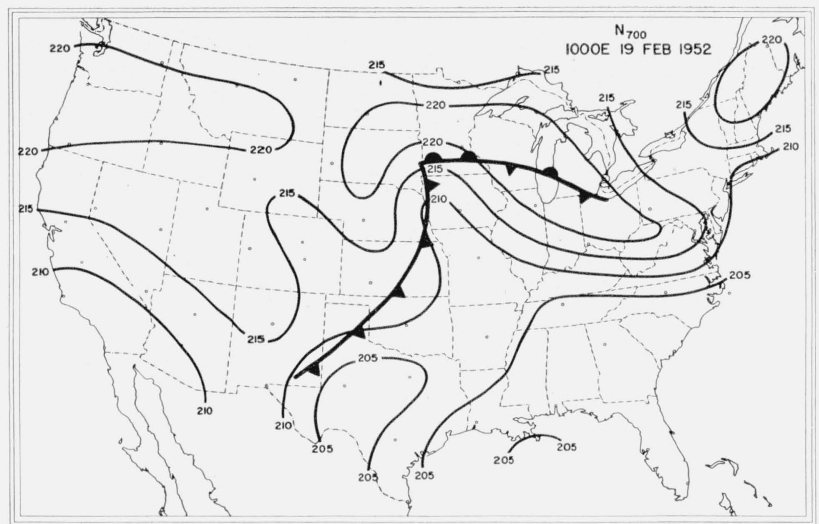

Figure 15. Radio refractivity at the $700-m b$ level 1000 e.s.t., 19 Feb. 1952.

prisingly enough, by the time the frontal system is well developed, at 1000 e.s.t. on the 20 th, the $\Delta N_{850}$ values are nearly as large as those on the surface.

The 700-millibar charts appear to be a bit more difficult to interpret than those of $N_{0}$ or $N_{850}$. It appears that at this altitude the wet term is usually negligible and $N$ will normally vary inversely as temperature since the pressure is, of course, constant at the $700-\mathrm{mb}$ level. By 1000 e.s.t. on the 19th an intrusion of low $N$ values is observed into the $700-\mathrm{mb}$ warm sector due to the advection of warm air northwards. The chart for $24 \mathrm{hr}$ later is interesting in that it displays two $N_{700}=225$ highs, one between the squall line and the cold front and the other just south of the apex of the $700-\mathrm{mb}$ wave. Interestingly enough, these two highs are due to quite different causes. The high centered over Atlanta appears to be due to the unusual transport of humidity to the $10,000-\mathrm{ft}$ level since the $700-\mathrm{mb}$ wet term at Atlanta increases from 4.5 to $25 \mathrm{~N}$ units in the 24 -hr period ending with 1000 e.s.t. on the 20 th. The second high centered over Omaha, appears to be due to an intense dome of cold air as indicated by the drop of the $700-\mathrm{mb}$ temperature from $-7.3^{\circ} \mathrm{C}$ to $-21.4^{\circ} \mathrm{C}$ in the twelve hours preceding the map time. The $\Delta N_{700}$ charts show this change more clearly.

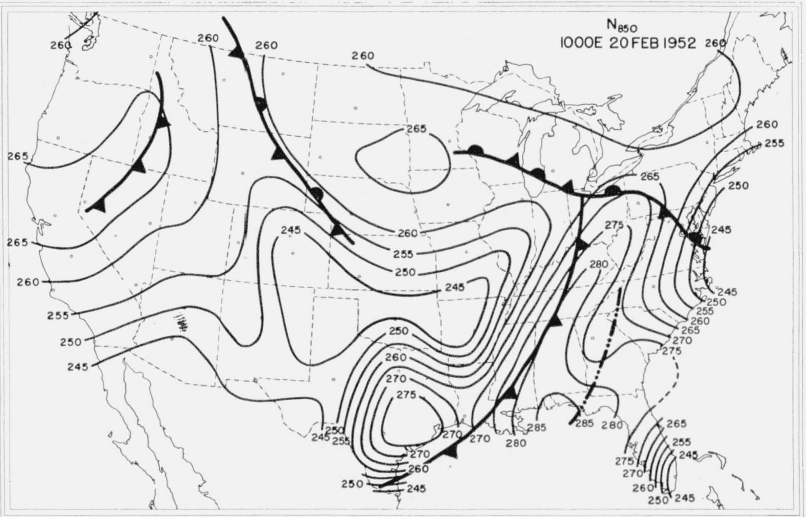

Figure 16. Radio refractivity at the 850-mb level 1000 e.s.t., 20 Feb. 1952. 


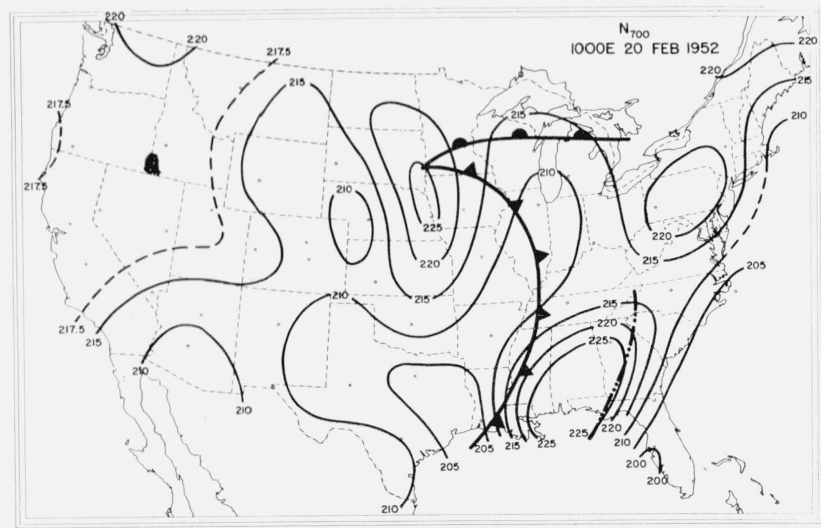

Figure 17. Radio refractivity at the 700-mb level 1000 e.s.t., 20 Feb. 1952.

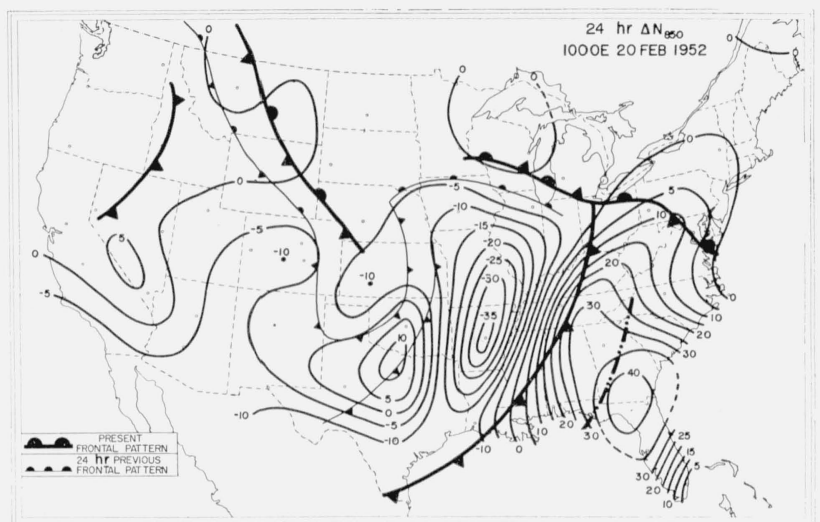

Figure 18. Change in the radio refractivity at the $850-m b$ level for the 24-hr period ending 1000 e.s.t., 20 Feb. 1952.

\section{Conclusions}

The present study indicates that the reduced-tosea-level value of the refractive index is a better indicator of synoptic weather changes than the unreduced value.

A systematic increase of this reduced value is observed in the warm sector of a developing polar front wave accompanied by a decrease behind the cold front. The present system had about a $+35 N$ unit rise and a $40 \mathrm{~N}$-unit drop. This general pattern might be expected to occur in all fast moving cold fronts with varying intensity depending upon the individual synoptic pattern. In any case, it appears that the $\Delta N_{0}$ pattern is a sufficiently stable and conservative property of the atmosphere so that it should be possible to develop forecasting rules for $N_{0}$ but not, of course, without analysis of many more $N$ patterns.

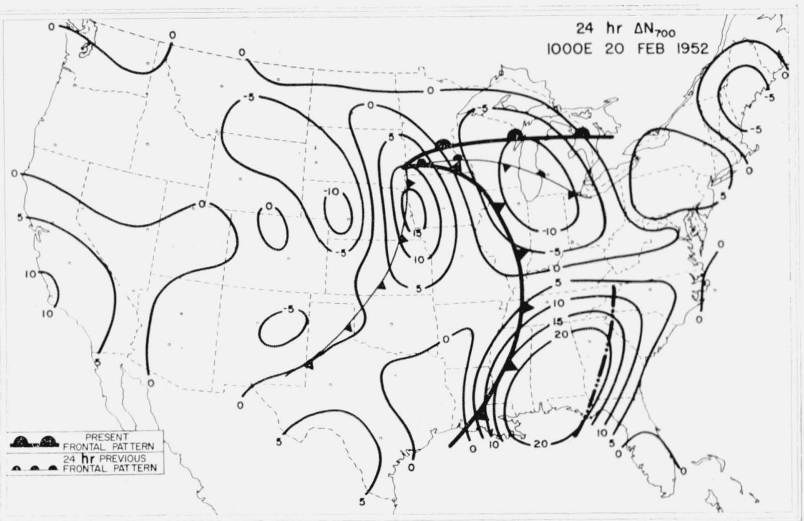

FIGURE 19. Change in the radio refractivity at the $700-m b$ level for the 24-hr period ending 1000 e.s.t., 20 Feb. 1952.

The authors express their appreciation to C. M. Miller for his preparation of the synoptic charts used in this report and to Miss G. Hoffmire for preparation of the manuscript.

\section{References}

[1] G. W. Pickard and H. T. Stetson, Comparison of tropospheric reception, J. Atmospheric and Terrest. Phys. 1, $32(1950)$.

[2] G. W. Pickard and H. T. Stetson, Comparison of tropospheric reception at 44.1 Me with 92.1 Me over the 167 mile path of Alpine, New Jersey, to Needham, Massachusetts, Proc. IRE 381450 (1950).

[3] B. R. Bean, Some meteorological effects on scattered radio waves, IRE Trans. PGCS. 432 (1956).

[4] M. Onoe, M. Hirai, S. Niwa, Results of experiment of long-distance overland propagation of ultra-short waves, J. Radio Research Labs. Japan 579 (1958).

[5] K. A. Norton, Point-to-point radio relaying via the scatter mode of tropospheric propagation, IRE Trans. PGCS-4, 39 (1956).

[6] R. E. Gray, The refractive index of the atmosphere as a factor in tropospheric propagation far beyond the horizon, IRE Nat. Conv. Record pt 1, 3 (1957).

[7] E. K. Smith, Jr. and S. Weintraub, The constants in the equation for atmospheric refractive index at radio frequencies, Proc. IRE 41, 1035 (1953).

[8] M. Schulkin, Average radio ray refraction in the lower atmosphere, Proc. IRE 40, 554 (1952).

[9] B. R. Bean and B. A. Cahoon, The use of surface weather observations to predict the total atmospheric bending of radio waves at small elevation angles, Proc. IRE 45, 1545 (1957)

[10] L. J. Anderson, Tropospheric bending of radio waves, Trans. Am. Geophys. Union 39, 208 (1958).

[11] B. R. Bean and G. D. Thayer, On models of the atmospheric refractive index, in Proc. IRE 5, 740 (1959).

[12] C. E. Palmer, Some kinematic aspects of frontal zones, J. Meteorol. 14, 403 (1957).

Boulder, Colo. (Paper 63D1-11). 